Journal of Education and Vocational Research (ISSN 2221-2590)

Vol. 7, No. 2, pp. 49-57, June 2016

\title{
Collaborative Provision of Graduate Education in CLMV: Case of Thailand's Private Universities
}

\author{
Lavanchawee Sujarittanonta, Kittichok Nithisathian, John C. Walsh \\ School of Management, Shinawatra University, Thailand \\ jcwalsh100@hotmail.com
}

\begin{abstract}
Education entails investments in time and money from the students and, therefore, the choices of degree programs and university names are critical for students and their future careers. The demand for foreign education in the CLMV (i.e. Cambodia, Lao PDR, Myanmar and Vietnam) market is fast expanding, especially for international graduate programs. Equipped with foreign degrees, the human resources of the host CLMV countries are ready for international jobs with international standards. This situation attracts investments by foreign universities to enter CLMV countries to offer degree programs, such as MBA, MPA and $\mathrm{PhD}$. While Western universities are internationally recognized, the success of Asian universities operating within CLMV has not been studied. Consequently, this paper reports on research examining the success of Thai private universities that operate in CLMV countries, in particular Mynmar, which has only recently opened up to the world, as well as the developing prospects for Vietnam. Lao PDR and Cambodia. Data is collected through in-depth interviews of managers and students of international partner institutions of the host countries, through which Thai universities offer graduate degree programs. It is found that private Thai degree programs are welcomed in CLMV countries, while Thai degrees are favored over international Western degrees in terms of economic affordability and preferred over Chinese degree programs due to the socio-cultural perception that Chinese products are doubtful in quality. This is not surprising, considering that a 2014 study by the UNESCO Institute for Statistics (UIS) reported that among middle-income countries of Asia, Thailand and Malaysia lead the region when it comes to providing graduate education.
\end{abstract}

Keywords: Education, CLMV, private universities, quality

\section{Introduction}

Education entails investments in time and money from the students, therefore the choice of degree programs and university names are critical in the students' decision making. While Western universities are internationally recognized, the success of Asian university operating within CLMV has not been studied. This calls for further investigation, especially because among middle-income countries of Asia, it was found that Thailand and Malaysia lead the region when it comes to providing graduate education, according to a 2014 study by the UNESCO Institute for Statistics (UIS). Therefore, this research examines the success of Thai private universities that operate in CLMV countries, in particular Myanmar which has only recently opened up to the world, which in effect also touches upon the developing prospects for Laos, Vietnam and Cambodia. Given the socio-economic developments of the CLMV countries, correspondingly, the demand for foreign education in CLMV market is also fast expanding, especially for international graduate programs. Equipped with foreign degrees, the human resource of the host CLMV countries are prepared to compete for international jobs that comes with international standards and work pressures. Also, from the CLMV student's side, he/she feels more confident as a job applicant, in that one is likely to receive a higher pay if he/she graduated from a foreign university, especially for jobs with foreign companies.

This is a highly attractive business opportunity to expand the education market. It follows the education market trend of developing countries, as a lot of CLMV students who have studied overseas have become prominent and successful in the societies of their home countries. Successful alumni are generally the model to aspire towards, and are the living testimonials that emphasize the superior quality and integrity of international degree programs. This highly favorable market situation attracts investments by foreign universities to enter CLMV countries, in order to offer degree programs such as MBA, MPA and PhD. This research looks the international expansion of Thailand's graduate education through the experiences of selected private Thai universities to sample host countries of Myanmar, Vietnam and Cambodia. Data is collected through in-depth interviews of educational administrators from both the Thai and CLMV side where 
possible, as well as the opinions of the CLMV students enrolled in the Thai graduate degree programs that is offered in Myanmar.

\section{Literature Review}

Education quality among ASEAN and CLMV countries: Among middle-income countries of Asia, it was found that Thailand and Malaysia lead the region when it comes to providing graduate education, according to Chapman and Chien's (2014) study by the UNESCO Institute for Statistics (UIS). Nevertheless, taking the lead does not automatically suggest quality, efficiency and effectiveness. For example, a mismatch between Thai and Malaysian graduates and the human capital demands of the job market was found by Jimenez, Nguyen \& Patrinos' (2013) case study which looks at human capital development and economic growth of Malaysia and Thailand. It is unlikely that the graduate programs could adjust quickly enough to the market needs, even with the knowledge about the discrepancies between graduates' skill sets and the employers' expectations of new recruits. In addition, another factor to take into serious consideration for Asia is the declining birth rate. This social situation is happening not only in developed economies of the West, but also for S.E. Asia, especially among the middle class and upper middle class who have the economic power and social pressures to pursue postgraduate degrees. Low birth rate has various consequences impacting all spheres of society, and is thus taken very seriously by Asia governments, resulting in the development of new strategies by governments for the sake of the economy and factors of production, including new strategies for education.

The resulting decline in undergraduate enrolment has also led educational institutions and the government to begin focusing on developing graduate education. With fewer students in the undergraduate age group, the educational institutions have to remain in business by implementing a market development strategy, selling more to the existing group of student customers, i.e. postgraduate programs. Among ASEAN countries, statistics from the World Economic Forum 2013-2014 (Table 1) indicate that Singapore and Malaysia are the countries with the best education systems in ASEAN, followed by Brunei, Indonesia, Philippines and Laos. It might be surprising, but Thailand comes in at the $7^{\text {th }}$ place behind Laos. The World Economic Forum statistics suggest that among CLMV countries, Thailand's education would be attractive only for Cambodia, more attractive for Vietnam and most attractive for Myanmar.

\section{Table 1: Education system ranking in ASEAN}

\begin{tabular}{ll}
\hline Singapore & 5.8 \\
Malaysia & 5.0 \\
Brunei & 4.4 \\
Indonesia & 4.3 \\
Philippines & 4.3 \\
Laos & 4.0 \\
Thailand & 3.6 \\
Cambodia & 3.2 \\
Vietnam & 3.4 \\
Myanmar & 2.1 \\
\hline \multicolumn{2}{l}{ Source: Global Competitiveness Report 2013-2014 by the World Economic Forum }
\end{tabular}

Origin and development of overseas satellite campus: The success of British and American overseas campuses is largely due to the establishment of English as a global lingua franca. These satellite campuses extend long-standing arrangements for recruiting international students and build on existing alliances. Historically, the US model of an overseas campus featured a small centre dedicated to short-stay arrangements for expatriates (OECD 2004: 121). However, today, Asia has now become the focus of growth in international branch campuses after more than a decade of rapid expansion in the Middle East. Developing countries have also begun to establish international branch campuses in other developing regions (Sharma, 2012). However, fewer than $5 \%$ of students globally travel abroad to branch campuses for their education, and this figure will probably not increase much. A major issue in building a satellite campus relates to the balance between standardization and adaptation. How much should be identical across campuses, and how much should differ? You do not joke with education. You take it seriously. Think of your own children -would 
you rather have them taught by Mickey Mouse, or by Albert Einstein? Better play hard with the former outside campus, and work hard with the latter inside, right? So those institutions that provide education must accept a responsibility to ensure consistency in the quality and standards of their offering. Playing around with Mickey is fine, as long as you get back to work when it is time to.

The growth of branch campuses: The first idea is to analyze the forces of globalization that underlies the growth of branch campuses from the 1990s onwards. In fact, educational trade must be seen as a tool for soft power. You read that correctly. The central mission of overseas campuses, first and foremost, is of cultural colonization. When Pink Floyd sang "we don't need any education, we don't need any thought control", they anticipated the application of market rules to education, whereby students become customers and degrees are bought and sold. Most international branch campuses are located throughout Asia and the Middle East, in regions such as the United Arab Emirates, Qatar, Saudi Arabia, Singapore and Malaysia. These moves are mostly market-driven; approximately two-thirds of new universities in the Arab Middle East are private and nearly half are branches of Western, English-speaking institutions. It is time for Taiwan, Thailand and other Asian countries to reclaim their influence on the educational world and intensify their soft power. It is also time to put an end to the brain drain and lure Asian students to stay by receiving a foreign degree at home at considerably lower cost. We all know we can make it. All we have to do is to want it badly.

Potential for satellites of Taiwan and Chinese universities: Given the economic development of China, it suggests that university education offered by countries that are strong in Chinese language and culture would be desired by countries that aim to increase trade with China, particularly ASEAN and CLMV countries which have geographical proximity to China and Chinese heritage. The findings from this research on ASEAN (Thai) universities' branch/satellite campuses in CLMV also offer guidelines for Taiwan universities that may be planning to expand abroad, particularly to ASEAN and CLMV markets. In Taiwan, regular staff visits and meetings definitely help getting the working atmosphere right (Ennew, 2014; Hashim \& Leitner, 2014). And this is exactly the strategy currently being pursued by Taiwanese international universities that operating within Taiwan, which at present does not have overseas satellite campuses yet. To demonstrate the competitiveness and excellence of Taiwan private university's educational quality, the section below presents I-Shou University, an international Taiwan university, as a sample case for better understanding of Taiwan University's potential for setting up overseas satellite campus.

Case Study of a Taiwan University: I-Shou University's strengths and challenges: Established in 1986, IShou University is located in the suburban setting of the medium-sized town of Dash (population range: 10,000-49,999 inhabitants). Officially accredited by the Ministry of Education of the Republic of China and a sort of association of business schools (AACSB), I-Shou University is a large higher education institution. Guess how many students? Well, as far as we can remember, the enrollment range last year was between 10,000 and 15,000 students. I-Shou University offers courses and programs leading to recognized degrees such as bachelor degrees, master degrees, and doctorate degrees in several areas of study. It also has a drastic admission policy based on students' past academic record and grades. International applicants are eligible to apply for enrollment but will only be accepted if they demonstrate the intellectual power and creativity of the brightest minds, thereby impressing the selection committee. I-Shou University's mission is to train future business leaders and artistic geniuses. It is with such an objective that I-Shou recruits students from Mongolia, Vietnam, Korea, France, Haiti, Honduras, Japan, China, Thailand, Malaysia, Papua New Guinea and other countries. Unfortunately, since most of these students -save the Chinese and the Malaysian -come along with an extremely poor or even inexistent level of Chinese, they are doomed to follow whatever course is taught in English. Students chose I-Shou because we had early mover advantage and competent local recruitment from a trusted source. Increasing competition is making our position less secure.

The trouble is, the majority of teachers delivering courses in English are not native speakers of English, and students have no choice but struggle to understand the poor grammar and bizarre accent of staff from France, Greece, Austria, Serbia, Bulgaria and other fancy places. With teachers who deliver a lot alright, but always in funny voices, and exchange students unable to say "hello" or "thank you" in Chinese, imagine the picture... Where are we at here? What is going on? Is there a pedagogical algorithm of some sort to sort out this mess? In this paper, we do not just describe a situation or complain about an existing state of affairs; we provide deep, easily applicable solutions. It is quite clear that students take both the program and the school fees in 
consideration when applying. Experts in student recruitment have over the years refined Taiwan's strategy for attracting local and international students to the Taiwanese IMBA program, rather than alternative offers from the UK or the US. We constantly stress that newcomers will feel more comfortable in an English-taught program that still follows Taiwanese administrative regulations, including a denser timetable with a higher number of classes and seminars, full availability of teachers, respect of national holidays such as the Dragon Boat Festival and the Chinese New Year (when Western institutions tend to celebrate Christmas, Halloween and other heretic events), and better care for students broadly speaking.

We are fully devoted to helping graduate students find the job that best suits their needs. For those who wish to stay in Taiwan, we have solid connections with industries in the E-United group, of which our University itself is a part. Students looking for jobs in the steel industry, entertainment business and tourism will find incredible opportunities as soon as they graduate. Those who are seeking international careers can refer to our International Office, which in recent years has developed relationships with 134 businesses in over 12 countries, ranging from Mongolia to Haiti and Honduras. Our IMBA's reputation transfers management and leadership skills that usually exceeds employers' expectations, whether locally or on a global scale. Our students remember three main experiences: the first is the sheer beauty of our campus and the unquestionable quality of our facilities. They feel comfortable in our air-conditioned classrooms and virtually any sports or entertainment option is available to them, from tennis courts to swimming pool to shopping centre to the real-size casino on the top floor of our building! Even the design of gardens and palm tree-lined roads are soothing to the eye. The second has to do with food quality. Fancy a cup of Oolong tea, sitting in the sunset, waiting for your boyfriend or girlfriend you can see jogging on the tracks in front of you? e-Coffee will be for you. Feel like indulging in a 5-course meal where even Kong-pao chicken and shrimp omelet are served? The food court is your best bet. Want to encourage your boyfriend or girlfriend practice golf swings from a reclining chair, munching on fried chicken wings? City Light golf is just around the corner. The third memorable experience is the quality of the teaching staff -caring, smiling, knowledgeable beyond expectations, and available at all times. How's that for a perfect studying environment?

Degrees from Chinese universities have been improving in the recent past, but they still cannot compare to what we offer in Taiwan. The main reason is their culture of censorship -when you cannot Google information or find people on Face book and other global networks, you leave a large part of the world in an obscure chaos, and this world will be happy to move on without you. In Taiwan, by contrast, we encourage students to be curious and willing to learn from the world outside China. The students from Myanmar, Vietnam and Cambodia who study in our university are clearly aware of this limitation. Those who eventually decide to study in China are motivated by factors external to education -spicy Sichuan food, business opportunities or a boyfriend/girlfriend eagerly waiting for reunion. However, I do not believe this extends to education services in China: this is just my intuition... But to cut a long story short, please hear me when I say this, please trust me: cannot compare! From the case study above, it is evident that the road ahead is strewn with some of the toughest challenges, which include attracting and retaining host campus faculty, replicating the diversity and excellent of the student body, and countless issues related to adaptation and the management of soft power.

But the opportunities are priceless, in particular for university-industry collaborations. For instance, YaoTsungChih, the Education Counselor of the Department of International and Cross Strait Education at the Ministry of Education (MOE) in Taiwan, said that the MOE offered many opportunities for overseas Chinese students to work or continue studying in Taiwan after graduation. Yes, here is just one of the benefits of establishing and maintaining branch campuses! Students are able to apply and stay in Taiwan for work as long as they pass the assessment. Su-Zhen Lu, Deputy Director of the OCAC, provided a Face book account for the students to access event information relevant to the OCAC. Heng-Li Ho, a student from Macau, said that overseas Chinese students received great care from Asia University while they were studying in Taiwan. He regards Taiwan and Asia University as his second home and thanks Asia University for everything it did for overseas Chinese students (Chang 2015). Now imagine this sort of feeling becomes the rule rather than the exception! The Taiwanese initiatives show that the provision of graduate education for foreign students always represents a sound strategy for consolidating university-industry collaborations independently of any ethical considerations. 


\section{Methodology}

Data is collected through open-ended questions interview face-to-face and internationally via social media (Face book groups, Face book message, LINE application, Whatsapp application) to a total of 17 managers, educators, investment advisors, potential investors, lecturers and graduate students of international partner institutions of the host country through which Thai universities offer graduate degree programs. Content analysis was carried out on the interview data that were obtained. Therefore we could obtain graduate student respondents only from Myanmar. Information about Myanmar came from the involved stakeholders and informants as follows:

From the Thai side (3),

- 1 Thai university's academic program director who oversees the Myanmar satellite program at the main campus in Thailand

- 2 Thai lecturers from the Thai university who have been sent to teach at the Myanmar satellite campus.

- 1 British professor from the Thai university who has been sent to teach at the Myanmar satellite campus. From the Myanmar side (8),

- 1 Myanmese manager at the satellite campus in Myanmar

- And a total of 7 Myanmese graduate students of a Thai university's satellite campus in Myanmar (2 doctors, 1 government officer, 1 recent graduate without work experience, 2 managers from the private sector, 1 senior academician who is also a business consultant).

For Cambodia (2) and Vietnam (1), here is no Thai satellite campus yet, and hence there are not any local graduate students of our specific scope in existence from Cambodia and Vietnam to interview yet. Nevertheless, this research chose the next best alternatives:

- For Cambodia this study interviewed 2 potential Thai investors who are each currently planning to open satellite campuses of Thai institutions in Cambodia (i.e. 2 different Thai institutions).

- For Vietnam, this research interviewed Singaporean investment consultant in Vietnam (1 person) who has been operating for over 10 years to advise Thai and other Asian investors about Vietnam business climate and market feasibility.

In addition, to cross check the information obtained for content validity and reduce respondent bias, additional (3) informants include:

- 2 international graduate students who are enrolled in Bangkok campus were also interviewed (Filipino and Nepalese).

- 1 French professor teaching international students at an international program offered by a Taiwanese international college in Taiwan.

The researcher could not find investors interested in operating a Thai postgraduate program in Laos yet. Questions for the non-Thai graduate students of the Thai satellite campus in Myanmar/ main campus in Thailand were as follows (adjust as appropriate to student's location):

Share your opinions please!

- Why did you choose this Thai university's MBA in Myanmar/Thailand, instead of other foreign/European MBA program in Myanmar/Thailand or back home?

- Now that you have graduated, how did the Thai university's MBA training help prepare you for your job/work?

- What parts of the experience about this Thai university's MBA do you remember and like?

- What about comparing to Chinese University's degree? What is your opinion of a degree from a Chinese University? Do Myanmar people have some perception that Chinese products are doubtful in quality? Will this doubt also include education services from China?

For the managers, educators and investors, the above questions were adjusted accordingly to suit each respondent's position:

Share your opinions please!

- Why do you think students (would) choose this Thai /Taiwan university's MBA in Myanmar, Vietnam, Cambodia, instead of other foreign/European MBA program in Myanmar, Vietnam, and Cambodia? 
- How do you think a Thai /Taiwan university's MBA training help prepare the local Myanmar, Vietnam, Cambodia students for their job/work (local job with local employer, local job with international employer, overseas job)?

- What parts of the experience about this Thai/Taiwan university's MBA do you think the students from Myanmar, Vietnam, and Cambodia would remember and like?

- What about comparing to Chinese University's degree? What is your opinion (and your students' opinion) of a degree from a Chinese University? Do people from Myanmar, Vietnam, and Cambodia have some perception that Chinese products are doubtful in quality? Will this doubt also include/extend to education services from China?

\section{Findings and Discussion}

At present, Thai universities operate graduate programs only in Myanmar, not in Cambodia Laos or Vietnam yet. Interviews with educators reveal that some Thai universities have collaboration with Laos universities at a lower level, such as sending lecturers to teach courses at the Laos universities. It is possible that the reason Thai universities do not have satellite campuses in Laos is because Laos has universities are seen to be of higher quality than Thai universities, as suggested by the World Economic Forum statistics from Table 1 which shows that Thailand is behind Laos when it comes to the quality of education. Due to the unique Myanmar political and economic transition situation, overseas universities have already entered to offer postgraduate level courses in Myanmar. Currently, the Thai universities running postgraduate programs through their Myanmar satellite campus (mainly MBA) are Assumption Business Administration College (ABAC) of Assumption University, University of the Thai Chamber of Commerce (UTCC), Stamford University, and Shinawatra University (SIU). Siam university does not have a satellite campus or center in Myanmar, but has contract with local Myanmar institutions to send students across to study in their Bangkok campus. The director for overseas satellite campus of Thai university in Myanmar also informed the researcher that the regulations pertaining to education in Vietnam is highly complicated, such that there is only one international university from Australia that managed to open a campus in Vietnam, namely, the Royal Melbourne Institute of Technology (RMIT). Content analysis of the interview data produced the following findings, which are then discussed.

Myanmar: Being able to attend classes locally is definitely much more convenient for the student e.g. "has lower costs while staying in our place". But the reason why Myanmar graduate students specifically chose a Thai university degree is of interest here. It was found that Thai universities have a good reputation and are held in high regard, surprisingly even when compared to Western universities. For example, a medical doctor who chose to study a Thai MBA program in Myanmar said that he chose the Thai MBA program "because it is accredited in Thailand and internationally recognized. For UK or European universities in Mandalay, it would be hard to access their quality, particularly whether they are actually recognized or not." Thai university is also seen as international, e.g. The Thai university "is an international university."

Notably, in addition to schedule and cost, the most cited reasons for choosing the Thai MBA program in Myanmar is because Thai satellite programs sends internationally trained foreign lecturers, whereby even a Thai teacher is considered foreign and definitely preferred over Myanmese teachers:

"because the other foreign MBA in Mandalay rent local teachers" i.e. to reduce operating cost.

"because of schedule, fee and especially qualified teachers." ... "is the only choice for learning with qualified foreign teachers in fair cost within short term?"

"Fully conducted by International Qualified Lecturers. Course fee is affordable. Course duration is reasonable." "because of schedule, reasonable fees, $100 \%$ foreign lecturer."

When it comes to Chinese universities, the Myanmar graduate students have interesting opinions, in that they relate Chinese universities with poor English, and tends to require being competent in Chinese language as well, e.g.

"Chinese university....They opened Chinese schools in Mandalay. Usually used in Chinese language...very weak in English".

"To study Chinese education, we need to study Chinese language first. This is the greatest barrier for Myanmar student I think." 
However from another perspective by the British Professor, Chinese degree is predicted to be desirable by the Myanmar students, given the power of Chinese investments in Myanmar, "many students have thought about the possibility of going to China. Mandalay is flooded with Chinese capital now, since it controls new shopping centres, hotels, hospitals and many other things."And university ranking comes into consideration, and yet if it was to be a Chinese degree, the student would prefer to go to China rather than attend a satellite campus at home and emphasize that it would have to be at an outstanding (not just any ordinary Chinese university which are deemed to be doubtful), e.g.

"Regarding Chinese universities, I would like to choose MBA programs from highly or moderately ranked ones because they are internationally recognized and are taught in English. But for ordinary Chinese universities, I am in doubt regarding their quality.....For Chinese universities, I would prefer going China to study."

Also, in Myanmar, Thai products are preferred for having higher quality compared to Chinese products. This is possibly because in general, Chinese products that are exported to Asia is not always the top quality, "Quality may be low (I bought one Chinese tie and students told me not to put it in the washing machine with other clothes, for example)".Or perhaps the Chinese products that are imported into Myanmar are only those of lower prices and lower quality. Unfortunately, this perception of Chinese products also can extend to Chinese education services, e.g.

"Chinese university is not popular in Myanmar and compare with China products Thailand products are good quality compare with China teacher."

For the second question about how well the Thai university's satellite campus helped to prepare them for their jobs, the answers focused on how the MBA courses helped them to develop a business mindset, and the prospects of high profile jobs, e.g.

"Today, most of the high profile jobs demand MBA and I believe .... MBA would be a stepping stone to my future career journey."

"MBA study helps me a lot in my professional field. The teaching method of ... helps me to improve management skills, critical thinking and business minds. Before MBA, in my mind how to treat patients? After MBA how to find money? This is the big change."

"MBA program enables to gain a critical perspective on our own management style and the insight to move out career forward."

"I had no idea or no experience about business, marketing etc. in the past. Now, I could promote my knowledge and my skill through MBA course. I applied the experience and the thoughts especially HR, Research Method, Critical Thinking, Cross Cultural etc. at my job."

Compared to local universities, the Thai satellite campus had strengths in different teaching methods:

"Teaching method is quite different from local universities where there is an emphasis on memorization of school lessons".

"I remember debate, controversial, knowledge sharing and learned from teachers course....teaching method for students' oriented".

"The most I like experience is Critical Thinking."

"Remember different teaching styles and knowledge sharing of our all lovely teachers, Group assignments times".

Cambodia: For Cambodia, the two potential investors suggest that enrolling in a Thai university that opens in Cambodia has advantages over Western graduate (MBA) program in Cambodia due to Cambodia's trade prospects and geographical proximity to Thailand, focusing Thai language in particular:

"...should teach Thai language together with the big Thai companies that invest in Cambodia, give students opportunities to do paid internships, looking from the advertisements looking for 100s of positions recruiting people who graduated from Thai language programs"

From Taiwan university's perspective, MBA programs all over the world are similar, but it is the teachers that make the difference, e.g. "The only real difference is in the quality of the faculty delivering the courses. We have mixed levels of ability in this case, in part because of low budget for hiring faulty members where we do not have in-house capacity." 
When it comes to the advantages that a Thai university's MBA training would have in helping to prepare the Cambodian student for his/her job/work, it was found to also emphasizes "Thainess" and working well with Thai people, e.g.

"Only in understanding Thai culture and form relationships with Thai, increase opportunities for doing business, and business connections with Thailand in general".

"The students will remember a lot of things about Thailand from the Thai teachers." "The other day, someone from HomePro said they are going to open in Cambodia, and asked me to help recruit staff, so that Thai companies (in Cambodia) will no longer have recruitment problems" (Note: HomePro is a multinational home improvement store that has several outlets in Thailand)

"The opportunity to do internship in Thailand, to learn Thai language, and work with Thai people, because Thailand is close to Cambodian's home".

When it comes to Chinese university's degree, the investor's opinion is that Thai language is still the main requirement because Cambodians focus on working for Thai companies. And even though supplementary Chinese language is also useful when communicating with Chinese business partners and clients, e.g.

"Cambodians also learn Chinese language, but if the Chinese university also teaches Thai language they will solve problems here, and emphasize their students to work with Thai companies, and sometimes use Chinese language to represent Thai companies when dealing with Chinese business partners"

"From my experience, Cambodians are interested in learning Chinese, even my maid can speak some Chinese. But the emphasis on Thai language is because Thai people do not use English. Cambodians also trade a lot with the Chinese, so if Cambodians can speak Chinese to Thai people, they will have more job opportunities, study both Thai and Chinese!"

When it comes to the perception of Chinese products, "most of the goods sold in Cambodia are from China", but "in Cambodia, things are more expensive than in Thailand".

Vietnam: For Vietnam, there are still many unanswered questions, according to the investment consultant for investors to Vietnam, e.g. "First, it's about how far the degree from a Thai university is being recognized in VN. Then it's about how much cheaper is it compared to be studying in an Australian university. Australian University is the top option for Vietnamese. Then come UK unis. UK unis are mainly for the richer Vietnamese. If VN do MBA, it is normally a UK MBA a preferred choice. Similar to Cambodian students, Vietnamese students emphasizes future business opportunities when they choose a Thai university degree, e.g. "VN will like to study in a Thai uni only if it helps them in their interest / business relations or anything which might bridge a profitable future."

Because Vietnam is historically and culturally closely linked with China, and continues to have high trade volume with China, a Chinese university degree would be preferred by a Vietnamese over a Thai university degree, i.e. "Chinese Unis may be a better option than Thai; putting politics aside, Chinese and Vietnamese do have very strong trade exchange. Many VN are now learning to speak Chinese".

International students studying in Thailand: Sample opinions of international students at graduate international program of the Thai university studying in Thailand, it is about suitable class schedule, diversity, and interesting teaching and learning methods, e.g. "runs the course during the weekend and it fits into my schedule as I work full time", "to study with professors with diverse viewpoints and approaches", "bringing in speakers in class. We cannot get everything from books and it is one great initiative to invite and learn from hands-on people who can share their personal experiences related to the course".

\section{Conclusion}

Thai universities can support as much as 120,000 students, yet high school graduates entering universities in 2016 are less than 100,000 . Therefore, private universities are fiercely fighting for student enrollment numbers, and one way to deal with the dwindling student population is to open satellite campuses overseas. Among middle-income countries of Asia, while it was found that Thailand and Malaysia lead the region when it comes to providing graduate education (UNESCO UIS 2014), Malaysia has not been investing in education in CLMV countries, unlike Thailand. It is likely that this due to cultural similarities, in that Myanmar, Cambodia and Thailand are both strongly Buddhist countries; Vietnam also has a long historical tradition of Buddhism, while Malaysia is a strongly devout Muslim country. Even then, national demand for graduate education is 
still insufficient, particularly for self-supporting private universities who now have to look internationally for graduate students. This development supports the vision of Thailand's Office of the Higher Education Commission (OHEC) which aims to develop Thailand as the education hub of the Association of Southeast Asian Nations (ASEAN).

Findings suggest that the successful market entry and operation of Thai graduate degrees results from educational regulatory constraints of the host countries, as well as socio-cultural norms in preference of a foreign graduate degree. Moreover, the experience of Thai private universities has implications for overseas expansion of graduate programs by private universities from Taiwan and other East-Asia and Pacific countries. This research found that in CLMV countries, private Thai degree programs are welcomed the most in Myanmar and Cambodia, while Chinese and hence Taiwanese degree programs would be more welcomed in Vietnam. Laos has not been adequately examined by this research, but is unlikely to be a potential market, given the statistics from World Economic Forum that supports the superiority of Laos educational system over that of Thailand. Thai degrees are favored over international Western degrees by Myanmar in terms of economic affordability, and Myanmar students preferred Thai over Chinese degree programs due to Myanmese' socio-cultural perception that Chinese products are doubtful in quality. Cambodians, however, are more interested in a Thai university degree not because it is "international" (the way how Myanmar graduate students perceive Thai university degree), but Cambodians focus on the business prospects with Thailand, hence they would enroll in a Thai degree program in order to learn the Thainess, nuanced knowledge about Thailand, and Thai language. Thailand's image is still rather highly positive among CLMV countries, even though among ASEAN, Thailand is not of the highest quality. Nevertheless, Thai degree tuition fees are not too

high compared to neighboring countries. Given the pressure to penetrate oversea market, the reputation of Thailand among CLMV and competitive pricing are key to making Thai postgraduate degrees expand in CLMV countries, perhaps even more successfully than Singapore and Malaysian postgraduate satellite degree programs.

\section{References}

Ennew, C. (2014). Why it still Makes Sense to Build an Overseas Campus, The Guardian, $25^{\text {th }}$ February.

Chang, S. L. (2015). Asia University Holds a Year-End Party for Overseas Chinese Students and Teachers, Asia Hot News, $2^{\text {nd }}$ March.

Chapman, D. W. \& Chien, C. L. (2014). Higher Education in Asia: Expanding Out, Expanding Up - The Rise of Graduate Education and University Research.

UNESCO Institute for Statistics, UN. ISBN 978-92-9189-147-4 DataLinkhttp://dx.doi.org/10.15220/978-929189-147-4-enhttp://www.uis.unesco.org/Library/Documents/higher-education-asia-graduateuniversity-research-2014-en.pdf Last accessed on 30 June 2016

Hashim, A. \& Leitner, G. (2014). English as a lingua franca in higher education in Malaysia. The Asian Journal of Applied Linguistics, 1(1), 16-27.

Jimenez, E., Nguyen, V. T. \& Patrinos, H. A. (2013). Human capital development and economic growth in Malaysia and Thailand, in Human Capital Formation and Economic Growth in Asia and the Pacific, Routledge: New York, USA, 141.

OECD. (2004). Internationalization and Trade in Higher Education: Opportunities and Challenges, New York: Centre for Educational Research and Innovation.

Sharma, Y. (2012). Branch Campus Growth has moved to Asia. University World News, 419(204), 13-15. 